\title{
Níveis de fósforo disponível e cálcio em rações suplementadas com fitase para frangos de corte nas fases de crescimento e final ${ }^{1}$
}

\author{
Luziane Moreira dos Santos ${ }^{2}$, Paulo Borges Rodrigues ${ }^{3}$, Renata Ribeiro Alvarenga ${ }^{2}$, Luciana \\ de Paula Naves ${ }^{2}$, Renato Hespanhol ${ }^{4}$, Gustavo Freire Resende Lima ${ }^{4}$, Maria Cecília Coelho \\ Lara $^{4}$, Leonardo Rafael da Silva ${ }^{4}$
}

1 Projeto financiado pelo CNPq e apoio da FAPEMIG (PPM).

2 Programa de Pós-Graduação em Zootecnia da Universidade Federal de Lavras (UFLA).

${ }^{3}$ Departamento de Zootecnia - UFLA. Bolsista do CNPq e membro do INCT - CA.

${ }^{4}$ Graduação em Zootecnia - UFLA. Bolsistas - IC/CNPq; AT/CNPq; PIBIC/FAPEMIG e PIBIC/CNPq.

RESUMO - Avaliaram-se os níveis de cálcio e fósforo disponível (Pdisp) em rações com fitase para frangos de corte da linhagem Cobb nas fases de crescimento (22 a 35 dias) e final (36 a 42 dias). Utilizou-se um esquema fatorial $3 \times 4+1$, composto de três níveis de Pdisp $(0,36 ; 0,31 ; 0,26 \%$ na fase de crescimento e 0,$33 ; 0,28 ; 0,23 \%$ na final), quatro níveis de cálcio $(0,82$; 0,$72 ; 0,62 ; 0,52 \%$ para a fase de crescimento e 0,$76 ; 0,66 ; 0,56 ; 0,46 \%$ para a final) e um nível de suplementação da fitase (500 ftu/kg). As rações controle não foram suplementadas com fitase e continham, respectivamente, os seguintes níveis de Pdisp e cálcio: 0,41 e $0,82 \%$ (fase de crescimento) e 0,38 e $0,76 \%$ (final). Nos ensaios de desempenho, aos 35 e 42 dias de idade, avaliaram-se o consumo de ração, o ganho de peso, a conversão alimentar e o teor de cinzas na tíbia. Nos ensaios de metabolismo, foram determinados os valores energéticos das rações (EMAn) e os coeficientes de metabolizabilidade da matéria seca (CMMS). Na fase de crescimento, a redução do cálcio e Pdisp para 0,52 e 0,26\%, respectivamente, não comprometeu o desempenho, a mineralização óssea, a EMAn e o CMMS. Na fase final, a redução do cálcio e fósforo disponível para 0,56 e $0,28 \%$, respectivamente, não comprometeu o desempenho, a EMAn e o CMMS e melhorou a mineralização óssea. Os níveis de cálcio e fósforo disponível em rações para frangos de corte podem ser reduzidos para 0,52 e 0,26\% na fase de crescimento e 0,56 e 0,28\% na fase final desde que essa redução seja combinada com a suplementação de fitase no nível de $500 \mathrm{ftu} / \mathrm{kg}$ de ração.

Palavras-chave: cinzas ósseas, desempenho, enzima, exigência nutricional, metabolismo

\section{Calcium and available phosphorus levels in diets supplemented with phytase for broilers in the growing and finishing phases}

\begin{abstract}
Calcium and available phosphorus (aP) levels in diets with phytase for Cobb broilers in the growing (22 to 35 days) and finishing phases (36 to 42 days of age) were evaluated. A $3 \times 4+1$ factorial scheme, with three aP levels $(0.36$, $0.31,0.26 \%$ in the growing phase and $0.33,0.28,0.23 \%$ in the finishing phase), four calcium levels $(0.82,0.72,0.62,0.52 \%$ in the growing phase and $0.76,0.66,0.56,0.46 \%$ in the finishing phase), and one level of supplementation of phytase $(500 \mathrm{ftu} / \mathrm{kg})$ was used. Control diets were not supplemented with phytase and they contained, respectively, the following levels of aP and calcium: 0.41 and $0.82 \%$ (growing phase) and 0.38 and 0.76 (finishing phase). In the performance assays, at 35 and 42 days of age, feed intake, weight gain, feed conversion and the ash content in the tibia were evaluated. In the metabolic assays, the energy values of diets (AMEn) and dry matter digestibility coefficients (DMDC) were determined. In the growing phase, the reduction of the calcium and aP to 0.52 and $0.26 \%$, respectively, did not compromise performance, bone ash, AMEn or MCDM In the finishing phase, the reduction of the calcium and aP to 0.56 and $0.28 \%$, respectively, did not compromise performance, AMEn or MCDM; in addition to improving bone ash. The levels of calcium and aP of diet can be reduced to 0.52 and $0.26 \%$ in the growing phase, and to 0.56 and $0.28 \%$ in the finishing phase, provided that this reduction is combined with supplementation of fitase at $500 \mathrm{ftu} / \mathrm{kg}$ of the diet
\end{abstract}

Key Words: bone ash, enzyme, metabolism, nutritional requirements, performance

\section{Introdução}

O fósforo (P) é um importante mineral estrutural, pois está presente nos componentes fosfatados das membranas celulares, estrutura óssea, DNA, RNA, ATP, entre outros, além de participar de importantes processos fisiológicos e enzimáticos. A deficiência desse mineral afeta o crescimento das aves, causando prejuízos econômicos (JordãoFilho etal., 2006). 
As rações para aves são compostas basicamente de ingredientes de origem vegetal, entretanto, as plantas armazenam a maior parte do fósforo na forma de fitato, que é aproveitado apenas na presença de fitase. Essa enzima não é produzida pelos monogástricos e tem sido suplementada (fonte exógena) nas rações como alternativa para melhorar o aproveitamento do fósforo fítico, cálcio e outros minerais influenciados pelo fitato. Segundo Choct (2006), o uso da fitase pode disponibilizar entre 25 e $70 \%$ do fósforo fítico.

Diversos trabalhos comprovaram a eficácia da fitase, comprovando que é possível reduzir nutrientes das rações sem comprometer o desempenho das aves e diminuindo a excreção de alguns elementos minerais (Gomide et al., 2007; Nagata et al., 2009; Silva et al., 2006; Silva et al., 2008). Entretanto, a atividade da fitase é influenciada por diversos fatores, como as matérias-primas vegetais utilizadas na formulação da ração e os níveis de cálcio e fósforo inorgânico da dieta (Ballam et al., 1984). Segundo Mitchell \& Edwards Junior (1996), devem-se manter os níveis de fósforo e cálcio inorgânicos nos limites mínimos necessários para maior solubilização do fitato no trato digestivo da ave. Já Schoulten et al. (2003) verificaram que, ao suplementar as rações com fitase, os níveis de cálcio e fósforo inorgânico devem ser reduzidos proporcionalmente, pois elevados níveis de cálcio podem reduzir a atividade da fitase diminuindo a absorção de minerais, como o cálcio, fósforo, zinco e manganês.

Portanto, para aproveitar os benefícios que o uso da fitase pode trazer para a avicultura, torna-se necessária a revisão dos níveis de inclusão de nutrientes que, além do fósforo, são comprovadamente afetados pelo uso dessa enzima, como o cálcio.

Assim, conduziu-se esse trabalho com o objetivo de avaliar em frangos de corte da linhagem Cobb nas fases de crescimento ( 22 a 35 dias) e final ( 36 a 42 dias de idade) o efeito de rações contendo diferentes níveis de fósforo disponível e cálcio (suplementadas com $500 \mathrm{ftu} / \mathrm{kg}$ ) sobre o desempenho das aves, o conteúdo de cinzas ósseas, a energia metabolizável aparente corrigida pelo balanço de nitrogênio e o coeficiente de metabolizabilidade da matéria seca.

\section{Material e Métodos}

Dois experimentos foram realizados com frangos de corte da linhagem Cobb (de 22 a 35 e 36 a 42 dias de idade) no Setor de Avicultura do Departamento de Zootecnia da Universidade Federal de Lavras. Cada experimento constou de um ensaio de metabolismo e um de desempenho e foi conduzido isoladamente para evitar possíveis efeitos residuais de uma fase sobre a outra. Em todos os ensaios, a ração (cuja composição dos ingredientes está descrita na Tabela 1) e a água foram fornecidas à vontade e a iluminação foi constante ( 24 horas de luz natural e/ou artificial).

$\mathrm{Na}$ fase de crescimento, o ensaio foi conduzido em delineamento inteiramente casualizado (DIC), com 4 repetições de 25 aves cada totalizando 1.300 pintos machos da linhagem Cobb recebendo ração padrão (Rostagno et al., 2005) até os 21 dias de idade. Ao completar 21 dias de idade, as aves foram pesadas, distribuídas em galpão convencional e alimentadas com as dietas experimentais no período de 22 a 35 dias de idade. Utilizou-se um esquema fatorial $3 \times 4+1$, composto de três níveis de fósforo disponível - Pdisp $(0,36$; $0,31$ e $0,26 \%)$, quatro níveis de cálcio $(0,82 ; 0,72 ; 0,62$ e $0,52 \%$ ) e um nível de suplementação de fitase ( $500 \mathrm{ftu} / \mathrm{kg}$ de ração) (Tabela 2). A ração controle não foi suplementada com fitase e foi formulada com $0,41 \%$ de Pdisp e $0,82 \%$ de cálcio, segundo recomendações nutricionais de Rostagno et al. (2005) (Tabela 2).

$\mathrm{Na}$ fase final, foram utilizados 1.040 pintos machos alimentados com uma ração padrão (Rostagno et al., 2005) até os 35 dias de idade. No $36^{\circ}$ dia, as aves foram pesadas e distribuídas nos boxes em 4 repetições de 20 aves. Este ensaio também foi conduzido em DIC no período de 36 a 42 dias de idade, em esquema fatorial $3 \times 4+1$, composto de três níveis de Pdisp $(0,33 ; 0,28$ e $0,23 \%)$, quatro níveis de cálcio $(0,76 ; 0,66 ; 0,56$ e $0,46 \%)$ e 500 ftu/kg de ração (Tabela 3$)$. A ração controle, sem fitase, continha $0,38 \%$ de Pdisp e $0,76 \%$ de cálcio (Tabela 3).

Considerando que dois terços do fósforo total do milho e farelo de soja estão na forma de fitato (aproximadamente $0,22 \%$ de P fítico) e que a fitase pode disponibilizar até $70 \%$ do fósforo fítico (Choct, 2006), programou-se a redução

Tabela 1 - Percentuais de matéria seca, proteína bruta, cálcio e fósforo total dos ingredientes utilizados nas rações experimentais ${ }^{1}$

\begin{tabular}{|c|c|c|c|c|}
\hline Ingrediente & Matéria seca & Proteína bruta & Cálcio & Fósforo total \\
\hline Milho & 90,91 & 8,20 & 0,05 & $0,24^{2}$ \\
\hline Farelo de soja & 88,71 & 47,33 & 0,32 & $0,55^{2}$ \\
\hline Fosfato bicálcico & “" & “ & 24,24 & 18,69 \\
\hline
\end{tabular}

${ }_{1}^{1}$ Valores determinados no Laboratório de Pesquisa Animal - DZO/UFLA.

${ }^{2}$ Considerou-se $1 / 3$ do fósforo total como disponível para as aves. 
Tabela 2 - Composição percentual e nutricional das rações experimentais ( 22 a 35 dias)

\begin{tabular}{|c|c|c|c|c|}
\hline \multirow[t]{3}{*}{ Ingredientes $(\mathrm{kg})$} & \multirow{3}{*}{ Controle $\mathrm{e}^{4}$} & \multicolumn{3}{|c|}{ Nível de fósforo disponível (\%) } \\
\hline & & 0,36 & 0,31 & 0,26 \\
\hline & & \multicolumn{3}{|c|}{ Nível de cálcio (\%) } \\
\hline Milho & 61,00 & 61,00 & 61,00 & 61,00 \\
\hline Farelo de soja & 31,70 & 31,70 & 31,70 & 31,70 \\
\hline L-lisina HCL 99\% & 0,17 & 0,17 & 0,17 & 0,17 \\
\hline DL-metionina $99 \%$ & 0,22 & 0,22 & 0,22 & 0,22 \\
\hline Premix mineral ${ }^{1}$ & 0,05 & 0,05 & 0,05 & 0,05 \\
\hline Premix vitamínico ${ }^{2}$ & 0,05 & 0,05 & 0,05 & 0,05 \\
\hline Anticoccidiano ${ }^{3}$ & 0,02 & 0,02 & 0,02 & 0,02 \\
\hline Calcário calcítico & 0,80 & $0,97 / 0,72 / 0,47 / 0,22$ & $1,13 / 0,88 / 0,62 / 0,38$ & $1,29 / 1,04 / 0,78 / 0,54$ \\
\hline \multicolumn{5}{|l|}{ Composição nutricional calculada } \\
\hline Energia metabolizável (kcal/kg) & 3100 & 3100 & 3100 & 3100 \\
\hline Proteína bruta $(\%)$ & 20,38 & 20,38 & 20,38 & 20,38 \\
\hline Lisina digestível (\%) & 1,07 & 1,07 & 1,07 & 1,07 \\
\hline Metionina + cistina digestível $(\%)$ & 0,77 & 0,77 & 0,77 & 0,77 \\
\hline Sódio (\%) & 0,18 & 0,18 & 0,18 & 0,18 \\
\hline Cálcio $(\%)^{5}$ & 0,82 & $0,82 / 0,72 / 0,62 / 0,52$ & $0,82 / 0,72 / 0,62 / 0,52$ & $0,82 / 0,72 / 0,62 / 0,52$ \\
\hline Fósforo disponível $(\%)^{5}$ & 0,41 & 0,36 & 0,31 & 0,26 \\
\hline
\end{tabular}

Tabela 3 - Composição percentual e nutricional das rações experimentais (36 a 42 dias)

\begin{tabular}{|c|c|c|c|c|}
\hline \multirow[t]{3}{*}{ Ingredientes $(\mathrm{kg})$} & \multirow{3}{*}{ Controle ${ }^{4}$} & \multicolumn{3}{|c|}{ Nível de fósforo disponível (\%) } \\
\hline & & 0,33 & 0,28 & 0,23 \\
\hline & & \multicolumn{3}{|c|}{ Nível de cálcio (\%) } \\
\hline Milho & 65 & 65 & 65 & 65 \\
\hline Farelo de soja & 28 & 28 & 28 & 28 \\
\hline L-lisina HCL 99\% & 0,22 & 0,22 & 0,22 & 0,22 \\
\hline DL-metionina $99 \%$ & 0,21 & 0,21 & 0,21 & 0,21 \\
\hline Premix mineral ${ }^{1}$ & 0,05 & 0,05 & 0,05 & 0,05 \\
\hline Premix vitamínico ${ }^{2}$ & 0,04 & 0,04 & 0,04 & 0,04 \\
\hline Anticoccidiano ${ }^{3}$ & 0,02 & 0,02 & 0,02 & 0,02 \\
\hline Calcário calcítico & 0,75 & $0,86 / 0,61 / 0,36 / 0,11$ & $1,03 / 0,78 / 0,52 / 0,27$ & $1,19 / 0,94 / 0,68 / 0,43$ \\
\hline Energia metabolizável ( $\mathrm{kcal} / \mathrm{kg})$ & 3145 & 3145 & 3145 & 3145 \\
\hline Proteína bruta $(\%)$ & 18,91 & 18,91 & 18,91 & 18,91 \\
\hline Lisina digestível (\%) & 1,02 & 1,02 & 1,02 & 1,02 \\
\hline Metionina + cistina digestível (\%) & 0,73 & 0,73 & 0,73 & 0,73 \\
\hline Sódio (\%) & 0,17 & 0,17 & 0,17 & 0,17 \\
\hline Cálcio $(\%)^{5}$ & 0,76 & $0,76 / 0,66 / 0,56 / 0,46$ & 0,76 & $0,76 / 0,66 / 0,56 / 0,46$ \\
\hline Fósforo disponível $(\%)^{5}$ & 0,38 & 0,33 & 0,28 & 0,23 \\
\hline
\end{tabular}


do Pdisp nas rações experimentais em até $0,15 \%(0,41 \%$ até $0,26 \%$ na fase de crescimento e $0,38 \%$ até $0,23 \%$ na fase final).

Aos 35 e 42 dias de idade, de forma independente para cada ensaio de desempenho, as rações e as aves foram pesadas para determinação do consumo de ração, do ganho de peso e da conversão alimentar. Além disso, ao final de cada período experimental, duas aves com peso médio da repetição foram abatidas para retirada da tíbia esquerda, usada posteriormente na determinação das cinzas ósseas. As tíbias, previamente identificadas com placas de alumínio, foram totalmente descarnadas e separadas da cartilagem proximal e fíbula. A quantificação das cinzas ósseas consistiu na incineração das tíbias (desengorduradas com éter etílico, moídas e homogeneizadas) por 6 horas a $600^{\circ} \mathrm{C}$ para determinação da porcentagem do resíduo.

Os ensaios de metabolismo foram conduzidos simultaneamente aos de desempenho. As aves foram alojadas em uma sala de metabolismo com temperatura controlada $\left(25^{\circ} \mathrm{C} \pm 3\right)$ contendo gaiolas em arame galvanizado (com dimensões de $50 \times 50 \times 50 \mathrm{~cm}$ ) providas de bandeja coletora de excretas forrada com plástico resistente. Os bebedouros utilizados foram do tipo infantil e os comedouros do tipo calha com borda para evitar desperdício.

No ensaio 2, 390 pintos machos Cobb 500 receberam ração padrão (Rostagno et al., 2005) até os 21 dias de idade. No $22^{\circ}$ dia, as aves foram pesadas, distribuídas nas gaiolas (em 6 repetições de 5 aves cada) e alimentadas com as rações experimentais (Tabela 2) até o 350 dia de idade.

No ensaio 4, 234 pintos machos receberam ração padrão (Rostagno et al., 2005) até os 35 dias de idade, quando foram pesados e distribuídos nas gaiolas (em 6 repetições de 3 aves cada). As rações experimentais (Tabela 3) foram fornecidas no período de 36 a 42 dias de idade.

Nos últimos três dias de cada ensaio de metabolismo, realizou-se a coleta total das excretas por unidade experimental, conforme descrito por Rodrigues et al. (2005).

A ração consumida durante o período de coleta foi registrada e as excretas coletadas diariamente foram acondicionadas em sacos plásticos e armazenadas em freezer até o final do período de coleta. Posteriormente, as excretas foram descongeladas, pesadas, homogeneizadas e secas em estufas de circulação de ar a $60{ }^{\circ} \mathrm{C}$ até peso constante. Em seguida, as amostras (rações e excretas) foram moídas e utilizadas para a determinação da matéria seca, nitrogênio e energia bruta, realizadas no Laboratório de Pesquisa Animal do Departamento de Zootecnia (UFLA). A energia bruta foi determinada utilizando-se uma bomba calorimétrica (modelo Parr-1261) e o teor de nitrogênio foi quantificado pelo método de Kjeldahl (AOAC, 2005).
Para os cálculos da energia metabolizável aparente corrigida pelo balanço de nitrogênio (EMAn) das rações, foram utilizadas as fórmulas descritas por Matterson et al. (1965) e, para determinação dos coeficientes de metabolizabilidade da matéria seca (CMMS), utilizou-se a seguinte fórmula:

CMMS $(\%)=(\underline{g \text { de matéria seca ingerida }-\mathrm{g} \text { de matéria seca excretada }) \times 100}$ $\mathrm{g}$ de matéria seca ingerida

Em todos os ensaios, as análises estatísticas foram realizadas com o uso do pacote computacional SAEG (UFV, 1993). Realizou-se análise de variância global com todas as dietas com o objetivo de obter o quadrado médio do resíduo e testar o fatorial. A ração controle foi comparada a cada uma das demais rações pelo teste de Dunnet a 5\%. Para comparação dos tratamentos no esquema fatorial, a 5\% de probabilidade, utilizou-se o teste de Student-NewmanKeuls (SNK) para os níveis de fósforo disponível e modelos de regressão para os níveis de cálcio.

\section{Resultados e Discussão}

Entre as aves que receberam ração contendo fitase e aquelas alimentadas com a ração controle, não houve diferença significativa $(\mathrm{P}>0,05)$ em nenhuma das características de desempenho avaliadas no período de 22 a 35 dias de idade (Tabela 4). Além disso, não houve interação $(\mathrm{P}>0,05)$ entre os níveis de Pdisp e cálcio da dieta para o consumo de ração, o ganho de peso e a conversão alimentar.

O consumo de ração diminuiu linearmente $(\mathrm{P}<0,05)$ com o aumento do nível de cálcio na ração, corroborando com os resultados de Edwards Junior (1993), Sebastian et al. (1996; 1997) e Qian et al. (1997). Por outro lado, houve efeito quadrático dos níveis de cálcio sobre o ganho de peso e a conversão alimentar $(\mathrm{P}<0,05)$, cujos piores valores foram estimados nos níveis de 0,72 e $0,68 \%$, respectivamente. Os níveis de Pdisp não influenciaram $(\mathrm{P}>0,05)$ nenhuma das características de desempenho das aves, assemelhando-se ao reportado por Laurentiz et al. (2007), os quais verificaram que a redução do nível de Pdisp na dieta de crescimento, associada à utilização da fitase, proporcionou resultados similares ao obtido com a ração controle.

Não houve diferença significativa $(\mathrm{P}>0,05)$ no teor de cinzas ósseas entre a ração controle e as demais dietas experimentais nem interação $(\mathrm{P}>0,05)$ entre os níveis de cálcio e Pdisp da dieta (Tabela 5).

Entretanto, os níveis de cálcio influenciaram de forma quadrática $(\mathrm{P}<0,01)$ a porcentagem de cinzas nas tíbias, cujo menor valor foi estimado para as aves alimentadas com a 
Tabela 4 - Desempenho de frangos de corte, no período de 22 a 35 dias de idade, alimentados com rações contendo fitase e diferentes níveis de fósforo disponível e cálcio

\begin{tabular}{|c|c|c|c|c|c|}
\hline \multirow[b]{3}{*}{ Fósforo disponível (\%) } & \multicolumn{5}{|c|}{ Consumo de ração $(\mathrm{g})$} \\
\hline & \multicolumn{4}{|c|}{ Cálcio (\%) } & \multirow[b]{2}{*}{ Média } \\
\hline & 0,82 & 0,72 & 0,62 & 0,52 & \\
\hline 0,31 & 2050 & 2086 & 2096 & 2150 & 2096 \\
\hline 0,26 & 2072 & 2061 & 2109 & 2155 & 2099 \\
\hline Média $^{1}$ & 2087 & 2088 & 2124 & 2152 & \\
\hline Coeficiente de variação (\%) & \multicolumn{5}{|c|}{$\begin{array}{c}\text { Ganho de peso }(\mathrm{g}) \\
\text { Cálcio }(\%)\end{array}$} \\
\hline Fósforo disponível (\%) & 0,82 & 0,72 & 0,62 & 0,52 & Média \\
\hline 0,36 & 1216 & 1192 & 1215 & 1223 & 1212 \\
\hline 0,31 & 1161 & 1152 & 1142 & 1204 & 1188 \\
\hline Coeficiente de variação (\%) & \multicolumn{5}{|c|}{$\begin{array}{c}\text { Conversão alimentar }(\mathrm{g} / \mathrm{g}) \\
\text { Cálcio }(\%)\end{array}$} \\
\hline Fósforo disponível (\%) & 0,82 & 0,72 & 0,62 & 0,52 & Média \\
\hline 0,36 & 1,76 & 1,78 & 1,78 & 1,76 & 1,77 \\
\hline 0,31 & 1,77 & 1,81 & 1,84 & 1,79 & 1,80 \\
\hline 0,26 & 1,77 & 1,81 & 1,77 & 1,73 & 1,77 \\
\hline Média $^{3}$ & 1,77 & 1,80 & 1,80 & 1,76 & \\
\hline Controle & & & & & 1,77 \\
\hline Coeficiente de variação (\%) & & & 2,35 & & \\
\hline
\end{tabular}

${ }^{1} \mathrm{CR}=2268,0-231,3 \mathrm{X}\left(\mathrm{R}^{2}=0,91\right)$.

${ }^{2} \mathrm{GP}=1969,5-2238,4 \mathrm{X}+1556,5 \mathrm{X}^{2}\left(\mathrm{R}^{2}=0,99\right)$.

${ }^{3} \mathrm{CA}=0,986+2,403 \mathrm{X}-1,767 \mathrm{X}^{2}\left(\mathrm{R}^{2}=0,99\right)$.

Tabela 5 - Teor de cinzas nas tíbias de frangos de corte aos 35 dias de idade recebendo rações com fitase e diferentes níveis de fósforo disponível e cálcio

\begin{tabular}{|c|c|c|c|c|c|}
\hline \multirow[b]{3}{*}{ Fósforo disponível (\%) } & \multicolumn{4}{|c|}{ Teor de cinzas $(\%)$} & \multirow[b]{3}{*}{ Média } \\
\hline & \multicolumn{4}{|c|}{ Cálcio (\%) } & \\
\hline & 0,82 & 0,72 & 0,62 & 0,52 & \\
\hline 0,31 & 50,35 & 48,73 & 47,88 & 47,86 & 48,71 \\
\hline 0,26 & 49,03 & 47,77 & 47,76 & 49,20 & 48,44 \\
\hline Média $^{1}$ & 49,95 & 48,36 & 47,99 & 48,80 & \\
\hline
\end{tabular}

${ }^{1}$ Cinzas ósseas $=72,523-76,948 \mathrm{X}+60,272 \mathrm{X}^{2}\left(\mathrm{R}^{2}=0,99\right)$.

ração com $0,64 \%$ de cálcio. Já os níveis de Pdisp não influenciaram $(\mathrm{P}>0,05)$ este parâmetro ósseo.

Os resultados deste trabalho estão de acordo com relatos de Schoulten et al. (2003) de que a exigência de cálcio e Pdisp para frangos, em rações suplementadas com fitase, é inferior aos níveis normalmente recomendados nas tabelas de exigências nutricionais quando não se utiliza fitase na ração. Isso comprova que a fitase foi eficiente em liberar fósforo fítico da ração, confirmando o relatado por Choct (2006). Portanto, é possível reduzir os níveis de cálcio e Pdisp da ração de crescimento (até 0,52 e 0,26\%, respectivamente) suplementada com fitase (500 ftu/ $\mathrm{kg}$ ) sem comprometer a mineralização óssea das aves e permitindo ainda desempenho semelhante ao observado quando se utiliza uma dieta controle, sem fitase, formulada com os níveis nutricionais recomendados por Rostagno et al. (2005).

Observa-se que as rações com $0,36 \%$ de Pdisp e 0,82 ou $0,62 \%$ de cálcio apresentaram EMAn inferior ao tratamento controle $(\mathrm{P}<0,05)$, embora este menor valor energético não tenha influenciado o desempenho das aves (Tabela 6). Por outro lado, a ração formulada com $0,82 \%$ de cálcio e $0,31 \%$ de Pdisp e aquela com $0,72 \%$ de cálcio e $0,26 \%$ de Pdisp 
Tabela 6 - Energia metabolizável aparente corrigida pelo balanço de nitrogênio (EMAn) e coeficiente de metabolizabilidade da matéria seca (CMMS) em rações de fase de crescimento com diferentes níveis de fósforo disponível e cálcio, suplementadas com fitase

\begin{tabular}{|c|c|c|c|c|c|}
\hline \multirow[b]{3}{*}{ Fósforo disponível (\%) } & \multicolumn{5}{|c|}{ EMAn (kcal/kg de MS) } \\
\hline & \multicolumn{4}{|c|}{ Cálcio (\%) } & \multirow[b]{2}{*}{ Média } \\
\hline & 0,82 & 0,72 & 0,62 & 0,52 & \\
\hline $0,36^{1}$ & $3233 * \mathrm{c}$ & 3517 & $3356 * \mathrm{~b}$ & $3410 b$ & 3379 \\
\hline $0,31^{2}$ & $3555 * a$ & 3484 & $3447 a$ & $3502 \mathrm{a}$ & 3497 \\
\hline $0,26^{3}$ & $3425 b$ & $3532 *$ & $3488 \mathrm{a}$ & $3460 \mathrm{ab}$ & 3476 \\
\hline Média & 3404 & 3511 & 3430 & 3457 & \\
\hline Controle & & & & & 3449 \\
\hline \multirow[t]{3}{*}{ Coeficiente de variação $(\%)$} & \multicolumn{5}{|c|}{1,35} \\
\hline & \multirow{2}{*}{\multicolumn{5}{|c|}{$\begin{array}{l}\text { CMMS (\%) } \\
\text { Cálcio (\%) }\end{array}$}} \\
\hline & & & & & \\
\hline Fósforo disponível (\%) & 0,82 & 0,72 & 0,62 & 0,52 & Média \\
\hline 0,36 & 75,88 & $77,29 \mathrm{ab}$ & 76,97 & $77,78 \mathrm{a}$ & 76,98 \\
\hline $0,31^{4}$ & 76,61 & $76,68 b$ & 75,24 & $74,67 \mathrm{~b}$ & 75,80 \\
\hline $0,26^{5}$ & 76,17 & $78,85 \mathrm{a}$ & 76,55 & $77,11 \mathrm{a}$ & 77,17 \\
\hline Média & 76,22 & 77,61 & 76,25 & 76,52 & \\
\hline Controle & & & & & 76,62 \\
\hline Coeficiente de variação $(\%)$ & 1,84 & & & & \\
\hline
\end{tabular}

* Difere do tratamento controle pelo teste de Dunnet $(\mathrm{P}<0,05)$.

Médias com letras distintas, na coluna, diferem entre si pelo teste SNK $(\mathrm{P}<0,05)$.

${ }^{1} 0,36 \%$ fósforo disponível. EMAn $=31081,6-131130 \mathrm{X}+204133 \mathrm{X}^{2}-104431 \mathrm{X}^{3}\left(\mathrm{R}^{2}=0,99\right)$.

$20,31 \%$ fósforo disponível. EMAn $=4743,54-4034,26 \mathrm{X}+3156,47 \mathrm{X}^{2}\left(\mathrm{R}^{2}=0,97\right)$.

$30,26 \%$ fósforo disponível. EMAn $=2055,03+4428,35 \mathrm{X}-3350,54 \mathrm{X}^{2}\left(\mathrm{R}^{2}=0,77\right)$

$40,31 \%$ fósforo disponível. CMMS $=70,9528+7,23519 \mathrm{X}\left(\mathrm{R}^{2}=0,87\right)$.

${ }^{5} 0,26 \%$ fósforo disponível. CMMS $=389,544-1471,04 \mathrm{X}+2270,72 \mathrm{X}^{2}-1148,67 \mathrm{X}^{3}\left(\mathrm{R}^{2}=0,99\right)$.

apresentaram EMAn superior ao tratamento controle $(\mathrm{P}<0,05)$, com incremento de até 3,07\% neste parâmetro energético.

Houve interação $(\mathrm{P}<0,01)$ entre os níveis de cálcio e Pdisp das dietas para a EMAn. Verificou-se efeito quadrático dos níveis de cálcio utilizando-se 0,31 e 0,26\% de Pdisp. Na ração com $0,31 \%$ de Pdisp, a menor EMAn foi estimada com $0,64 \%$ de cálcio; entretanto, ao reduzir o Pdisp para $0,26 \%$, o uso de $0,66 \%$ de cálcio proporcionou a maior EMAn estimada. Esses resultados indicam que o efeito da fitase sobre a EMAn é variável em função do teor de Pdisp e cálcio da ração, contudo, os mecanismos bioquímicos envolvidos são complexos e há necessidade de novos estudos para o entendimento dessa questão. Ressalta-se, ainda, que há dificuldade na comparação dos dados com a literatura, devido a resultados divergentes quanto à influência da relação Ca:Pdisp sobre a atividade da fitase e, por sua vez, seu efeito sobre a EMAn. Observou-se um efeito cúbico dos níveis de cálcio quando se utilizou $0,36 \%$ de Pdisp, com maior e menor EMAn estimadas em 0,73 e $0,82 \%$ de cálcio, respectivamente, embora o efeito cúbico não tenha uma explicação biológica clara.

Os níveis de Pdisp também influenciaram a EMAn $(\mathrm{P}<0,01)$ nas rações com $0,82 \%, 0,62 \%$ e $0,52 \%$ de cálcio, apresentando melhores resultados nas rações com $0,31 \%$ de Pdisp, nos respectivos níveis de cálcio mencionados, e com $0,26 \%$ de Pdisp e $0,62 \%$ de cálcio.
Ainda na Tabela 6, observa-se que nenhuma ração contendo fitase e reduzidos níveis de Pdisp e cálcio diferiu da ração controle $(\mathrm{P}>0,05)$, em relação ao coeficiente de metabolizabilidade da matéria seca (CMMS), corroborando com o relatado por Rocha et al. (2006) em pesquisa com aves de 1 a 7 dias de idade. Todavia, houve interação $(P<0,05)$ dos níveis desses nutrientes para o CMMS. Na ração com 0,31\% de Pdisp, houve aumento linear do CMMS em função de níveis crescentes de cálcio na ração, o que está de acordo com os resultados obtidos por Schoulten et al. (2003) que reduziram os níveis de cálcio em rações suplementadas com $600 \mathrm{ftu} / \mathrm{kg}$ e observaram prejuízo na digestibilidade da matéria seca. Entretanto, o CMMS apresentou resposta cúbica $(\mathrm{P}<0,01)$ aos níveis de cálcio quando se utilizou $0,26 \%$ de Pdisp, com maior e menor CMMS estimados em 0,74 e $0,57 \%$ de cálcio, respectivamente, embora o efeito cúbico não tenha uma explicação biológica clara. Em pesquisa semelhante, Cardoso Júnior et al. (2010) avaliaram o efeito da fitase $(500 \mathrm{ftu} / \mathrm{kg})$ sobre o coeficiente de metabolizabilidade da proteína bruta (CMPB) em rações para frangos de 8 a 35 dias de idade e verificaram que, na ração com $0,325 \%$ de Pdisp, o modelo cúbico foi o que melhor representou a influência do nível de cálcio (variando de 0,55 até $0,85 \%$ ) sobre o CMPB.

Os níveis de Pdisp influenciaram o CMMS apenas nos níveis de 0,72 e $0,52 \%$ de cálcio (Tabela 6), estimando-se melhores CMMS na ração com $0,72 \%$ de cálcio e $0,26 \%$ de 
Pdisp e nas rações com $0,52 \%$ de cálcio e 0,36 ou $0,26 \%$ de Pdisp.

De modo geral, no período de 22 a 35 dias de idade, as alterações na EMAn e no CMMS não acaretaram diferenças no desempenho e mineralização óssea das aves que receberam rações suplementadas com fitase (com reduzidos níveis de Pdisp e cálcio), em comparação ao tratamento controle.

O desempenho das aves que receberam dietas com fitase e reduzidos níveis de Pdisp e cálcio não diferiu $(\mathrm{P}>0,05)$ do tratamento controle (Tabela 7). Entretanto, houve interação $(\mathrm{P}<0,01)$ dos níveis de cálcio e Pdisp para o consumo de ração, ganho de peso e conversão alimentar.

$\mathrm{O}$ consumo de ração diminuiu linearmente $(\mathrm{P}<0,05)$ conforme aumentaram os níveis de cálcio da ração com 0,33\% de Pdisp, corroborando os resultados de Edwards Junior (1993), Sebastian et al. (1996; 1997) e Qian et al. (1997). Por outro lado, houve efeito cúbico $(\mathrm{P}<0,05)$ quando se reduziu o Pdisp para 0,28 e $0,23 \%$. Com 0,28\% de Pdisp, o maior e menor consumo de ração foram determinados com 0,46 e $0,76 \%$ de cálcio, respectivamente. Para $0,23 \%$ de
Pdisp, o maior e menor consumo de ração foram estimados com 0,55 e $0,46 \%$ de cálcio, respectivamente. Os níveis de Pdisp influenciaram o consumo de ração $(\mathrm{P}<0,05)$ quando a ração foi formulada com 0,$76 ; 0,56$ e $0,46 \%$ de cálcio. As aves consumiram mais quando as rações continham: 0,76\% de cálcio e $0,23 \%$ de Pdisp; $0,56 \%$ de cálcio e 0,33 ou $0,23 \%$ de Pdisp; $0,46 \%$ de cálcio e 0,33 ou $0,28 \%$ de Pdisp.

$\mathrm{O}$ ganho de peso respondeu linearmente $(\mathrm{P}<0,05)$ aos níveis de cálcio da dieta contendo 0,33 e $0,23 \%$ de Pdisp. Com $0,33 \%$ de Pdisp, houve aumento do ganho de peso das aves em função da redução do cálcio, corroborando resultados descritos por Qian et al. (1997) e Schoulten et al. (2003) de que doses crescentes de cálcio acarretaram redução linear do ganho de peso de frangos na fase inicial. Essa redução no ganho de peso de frangos de corte com a elevação do nível de cálcio da ração pode ser explicada pelo efeito antagônico do cálcio pode ter sobre a absorção de outros minerais. Além disso, há maior probabilidade de o cálcio complexar-se ao fitato reduzindo a atividade da fitase (Qian et al., 1997) e seu efeito benéfico na disponibilização de fósforo e outros nutrientes (Shafey et al., 1991). Já no

Tabela 7 - Desempenho de frangos de corte alimentados no período de 36 a 42 dias de idade com rações contendo fitase e diferentes níveis de fósforo disponível e cálcio

\begin{tabular}{|c|c|c|c|c|c|}
\hline \multirow[b]{3}{*}{ Fósforo disponível (\%) } & \multicolumn{5}{|c|}{ Consumo de ração (g) } \\
\hline & \multicolumn{4}{|c|}{ Cálcio (\%) } & \multirow[b]{2}{*}{ Média } \\
\hline & 0,76 & 0,66 & 0,56 & 0,46 & \\
\hline $0,33^{1}$ & $1308 b$ & 1405 & $1412 \mathrm{a}$ & $1425 \mathrm{a}$ & 1388 \\
\hline $0,28^{2}$ & $1307 \mathrm{~b}$ & 1393 & $1336 b$ & $1408 \mathrm{a}$ & 1361 \\
\hline $0,23^{3}$ & $1424 \mathrm{a}$ & 1379 & $1425 \mathrm{a}$ & $1328 b$ & 1389 \\
\hline Média & 1346 & 1392 & 1391 & 1387 & \\
\hline Controle & & & & & 1365 \\
\hline \multirow[t]{2}{*}{ Coeficiente de variação (\%) } & & & 3,64 & & \\
\hline & \multicolumn{5}{|c|}{$\begin{array}{c}\text { Ganho de peso }(\mathrm{g}) \\
\text { Cálcio }(\%)\end{array}$} \\
\hline Fósforo disponível (\%) & 0,76 & 0,66 & 0,56 & 0,46 & Média \\
\hline $0,33^{4}$ & $642 b$ & 702 & 680 & $711 \mathrm{a}$ & 684 \\
\hline 0,28 & $659 b$ & 684 & 644 & $688 \mathrm{a}$ & 669 \\
\hline $0,23^{5}$ & $718 \mathrm{a}$ & 712 & 691 & $634 b$ & 689 \\
\hline Média & 673 & 699 & 672 & 678 & \\
\hline Controle & & & & & 682 \\
\hline \multirow[t]{2}{*}{ Coeficiente de variação (\%) } & & & 4,58 & & \\
\hline & \multicolumn{5}{|c|}{$\begin{array}{c}\text { Conversão alimentar }(\mathrm{g} / \mathrm{g}) \\
\text { Cálcio }(\%)\end{array}$} \\
\hline Fósforo disponível (\%) & 0,76 & 0,66 & 0,56 & 0,46 & Média \\
\hline 0,33 & 2,04 & $2,01 \mathrm{ab}$ & 2,08 & 2,01 & 2,03 \\
\hline 0,28 & 1,98 & $2,04 \mathrm{a}$ & 2,08 & 2,04 & 2,04 \\
\hline $0,23^{6}$ & 1,98 & $1,94 b$ & 2,07 & 2,10 & 2,02 \\
\hline Média & 2,00 & 1,99 & 2,07 & 2,05 & \\
\hline Controle & & & & & 1,99 \\
\hline Coeficiente de variação (\%) & & & 2,54 & & \\
\hline
\end{tabular}

Médias com letras distintas, na coluna, diferem entre si pelo teste SNK $(\mathrm{P}<0,05)$.

${ }^{1} 0,33 \%$ fósforo disponível. $\mathrm{CR}=1606,01-358,00 \mathrm{X}\left(\mathrm{R}^{2}=0,74\right)$.

$20,28 \%$ fósforo disponível. $\mathrm{CR}=10907,5-48473,1 \mathrm{X}+80903,9 \mathrm{X}^{2}-44401,9 \mathrm{X}^{3}\left(\mathrm{R}^{2}=0,99\right)$.

$30,23 \%$ fósforo disponível. $\mathrm{CR}=-7439,72+43794,8 \mathrm{X}-71391,8 \mathrm{X}^{2}+38306,5 \mathrm{X}^{3}\left(\mathrm{R}^{2}=0,99\right)$

$40,33 \%$ fósforo disponível. $\mathrm{GP}=795,74-184,00 \mathrm{X}\left(\mathrm{R}^{2}=0,61\right)$.

$50,23 \%$ fósforo disponível. $\mathrm{GP}=520,965-274,750 \mathrm{X}\left(\mathrm{R}^{2}=0,85\right)$.

${ }^{6} 0,23 \%$ fósforo disponível. $\mathrm{CA}=2,30360-0,463943 \mathrm{X}\left(\mathrm{R}^{2}=0,67\right)$. 
menor nível de Pdisp utilizado (0,23\%), houve diminuição do ganho de peso quando se reduziu o cálcio na ração. Além disso, os níveis de Pdisp influenciaram o ganho de peso na aves alimentadas com as rações com 0,76 e $0,46 \%$ de cálcio. A ração com $0,76 \%$ de cálcio e $0,23 \%$ de Pdisp acarretou maior ganho de peso. Entretanto, com $0,46 \%$ de cálcio na ração, o maior ganho de peso das aves foi observado com 0,33 ou $0,28 \%$ de Pdisp.

O aumento dos níveis de cálcio na ração com $0,23 \%$ de Pdisp reduziu linearmente $(\mathrm{P}<0,05)$ a conversão alimentar das aves. Este resultado é contrário ao descrito por Sebastian et al. (1997), os quais verificaram piora na conversão alimentar com o aumento do nível de cálcio de rações suplementadas com fitase ( $600 \mathrm{ftu} / \mathrm{kg}$ ). Além disso, com $0,66 \%$ de cálcio na dieta a melhor conversão alimentar $(\mathrm{P}<0,05)$ foi determinada no nível de $0,23 \%$ de Pdisp.

O teor de cinzas nas tíbias dos frangos do grupo controle foi inferior $(\mathrm{P}<0,05)$ ao determinado nas aves que receberam as rações com $0,56 \%$ de cálcio e 0,33 ou $0,28 \%$ de Pdisp e a ração com $0,46 \%$ de cálcio e $0,28 \%$ de P disp (Tabela 8 ).

Houve interação dos níveis de cálcio e Pdisp na dieta $(\mathrm{P}<0,05)$. O teor de cinzas nas tíbias das aves respondeu de forma quadrática $(\mathrm{P}<0,05)$ aos níveis de cálcio quando se utilizou $0,33 \%$ de Pdisp, com maior porcentagem de cinzas estimada em $0,58 \%$ de cálcio. Contudo, com $0,28 \%$ de Pdisp, o teor de cinzas reduziu linearmente $(\mathrm{P}<0,01) \mathrm{em}$ função do aumento dos níveis de cálcio na ração. Qian et al. (1997) também verificaram que a mineralização óssea de frangos de corte foi afetada negativamente pelo aumento do nível de cálcio em ração à base de milho e farelo de soja suplementada com fitase.

No nível de $0,66 \%$ de cálcio, o maior teor de cinzas foi determinado no menor nível de Pdisp avaliado (0,23\%). Não houve diferença significativa $(\mathrm{P}>0,05)$ entre os níveis de Pdisp quando as rações continham 0,$76 ; 0,56$ ou $0,46 \%$ de cálcio.
Apenas a ração contendo $0,66 \%$ de cálcio e $0,28 \%$ de Pdisp apresentou EMAn inferior ao tratamento controle $(\mathrm{P}<0,05)$ com redução de 3,05\% (Tabela 9). Contudo, Lan et al. (2002) determinaram a energia metabolizável de rações com baixo nível de fósforo, à base de milho e farelo de soja, e verificaram que a adição de fitase microbiana (250 e $500 \mathrm{ftu} / \mathrm{kg}$ ) proporcionou valores de EMA superiores aos determinados na ração controle (com nível normal de fósforo e sem suplementação enzimática).

Houve interação dos níveis de cálcio e Pdisp das dietas $(\mathrm{P}<0,01)$, com efeito quadrático $(\mathrm{P}<0,01)$ dos níveis de cálcio quando associado ao nível de $0,33 \%$ de Pdisp, com menor EMAn estimada em $0,63 \%$ de cálcio. Todavia, a EMAn apresentou resposta cúbica aos níveis de cálcio nas dietas com 0,28 e $0,23 \%$ de Pdisp. Com 0,28\% de Pdisp, a maior e menor EMAn foram estimadas com 0,53 e $0,69 \%$ de cálcio, respectivamente. Para $0,23 \%$ de Pdisp, a maior e menor EMAn foram estimadas com 0,68 e 0,76\% de cálcio, respectivamente. Os efeitos cúbicos para a EMAn das rações com 0,28 e 0,23\% de Pdisp, (Tabela 9) assemelham-se aos modelos cúbicos propostos para o consumo de ração das aves (Tabela 7), indicando que os valores de EMAn estão correlacionados com o consumo de ração, embora sem uma explicação biológica clara até o momento.

Os níveis de Pdisp influenciaram a EMAn $(\mathrm{P}<0,01)$ das rações com 0,$66 ; 0,56$ e $0,46 \%$ de cálcio, verificando-se melhores resultados nas seguintes combinações: $0,66 \%$ de cálcio e $0,23 \%$ de Pdisp; $0,56 \%$ de cálcio e 0,28 ou $0,23 \%$ de Pdisp; $0,46 \%$ de cálcio e 0,33 ou $0,23 \%$ de Pdisp.

Apenas a ração com $0,46 \%$ de cálcio e $0,28 \%$ de Pdisp apresentou CMMS inferior $(\mathrm{P}<0,05)$ ao controle (Tabela 9). Além disso, houve interação entre os níveis de cálcio e Pdisp da dieta $(\mathrm{P}<0,01)$. Na dieta com $0,28 \%$ de Pdisp, o CMMS apresentou efeito quadrático $(\mathrm{P}<0,01)$ em função dos níveis de cálcio, com maior CMMS estimado em $0,68 \%$ de cálcio. Por outro lado, os níveis de Pdisp da dieta

Tabela 8 - Teor de cinzas nas tíbias de frangos de corte aos 42 dias de idade recebendo rações com fitase e diferentes níveis de fósforo disponível e cálcio

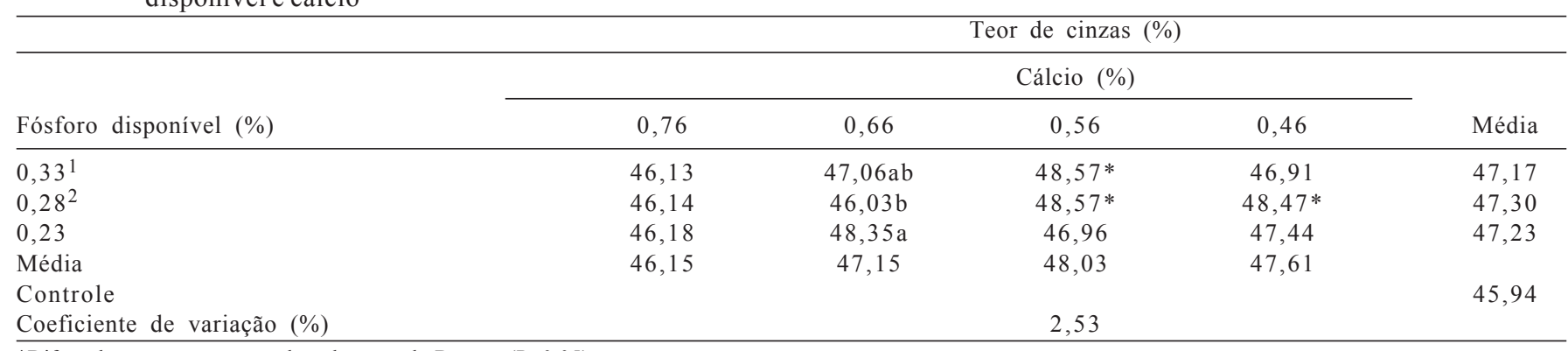

* Difere do tratamento-controle pelo teste de Dunnet $(\mathrm{P}<0,05)$.

Médias com letras distintas na coluna diferem $(\mathrm{P}<0,05)$ entre si pelo teste SNK.

${ }^{1} 0,33 \%$ fósforo disponível. Cinzas ósseas $=26,2300+75,1400 \mathrm{X}-64,7500 \mathrm{X}^{2}\left(\mathrm{R}^{2}=0,77\right)$

$20,28 \%$ fósforo disponível. Cinzas ósseas $=52,9349-9,31720 \mathrm{X}\left(\mathrm{R}^{2}=0,80\right)$ 
Tabela 9 - Energia metabolizável aparente corrigida pelo balanço de nitrogênio (EMAn) e coeficiente de metabolizabilidade da matéria seca (CMMS) em rações de fase final com diferentes níveis de fósforo disponível e cálcio suplementadas com fitase

\begin{tabular}{|c|c|c|c|c|c|}
\hline \multirow[b]{3}{*}{ Fósforo disponível (\%) } & \multicolumn{5}{|c|}{ EMAn (kcal/kg de MS) } \\
\hline & \multicolumn{4}{|c|}{ Cálcio (\%) } & \multirow[b]{2}{*}{ Média } \\
\hline & 0,76 & 0,66 & 0,56 & 0,46 & \\
\hline $0,33^{1}$ & 3466 & $3446 b$ & $3413 b$ & $3528 \mathrm{a}$ & 3463 \\
\hline $0,28^{2}$ & 3468 & $3369 * \mathrm{c}$ & $3504 \mathrm{a}$ & $3403 b$ & 3436 \\
\hline $0,23^{3}$ & 3476 & $3551 \mathrm{a}$ & $3488 \mathrm{a}$ & $3536 a$ & 3513 \\
\hline Média & 3470 & 3455 & 3468 & 3489 & \\
\hline Controle & & & & & 3475 \\
\hline \multirow[t]{3}{*}{ Coeficiente de variação (\%) } & \multicolumn{5}{|c|}{1,42} \\
\hline & \multicolumn{5}{|c|}{ CMMS (\%) } \\
\hline & \multicolumn{5}{|c|}{ Cálcio (\%) } \\
\hline Fósforo disponível (\%) & 0,76 & 0,66 & 0,56 & 0,46 & Média \\
\hline 0,33 & 76,67 & $76,44 \mathrm{ab}$ & 76,76 & $76,75 \mathrm{a}$ & 76,66 \\
\hline $0,28^{4}$ & 76,30 & $75,49 b$ & 76,51 & $73,70 * b$ & 75,50 \\
\hline 0,23 & 76,83 & $77,69 \mathrm{a}$ & 76,19 & $77,23 \mathrm{a}$ & 76,99 \\
\hline Média & 76,60 & 76,54 & 76,49 & 75,89 & \\
\hline Controle & & & & & 77,48 \\
\hline Coeficiente de variação (\%) & \multicolumn{5}{|c|}{1,44} \\
\hline
\end{tabular}

*Difere do tratamento controle pelo teste de Dunnet $(\mathrm{P}<0,05)$.

Médias distintas, nas colunas, diferem $(\mathrm{P}<0,05)$ entre si pelo teste SNK.

${ }_{1}^{1} 0,33 \%$ fósforo disponível. EMAn $=4774,61-4287,18 \mathrm{X}+3390,29 \mathrm{X}^{2}\left(\mathrm{R}^{2}=0,81\right)$.

$20,28 \%$ fósforo disponível. EMAn $=13602,9+86905,6 \mathrm{X}-144998 \mathrm{X}^{2}+79217 \mathrm{X}^{3}\left(\mathrm{R}^{2}=0,99\right)$.

$30,23 \%$ fósforo disponível. EMAn $=12426,7-45714,8 \mathrm{X}+76852,3 \mathrm{X}^{2}-42366,7 \mathrm{X}^{3}\left(\mathrm{R}^{2}=0,99\right)$.

${ }^{4} 0,28 \%$ fósforo disponível. CMMS $=53,3757+67,7925 \mathrm{X}-49,9979 \mathrm{X}^{2}\left(\mathrm{R}^{2}=0,68\right)$.

influenciaram o CMMS ( $\mathrm{P}<0,01)$ nos níveis de 0,66 e $0,46 \%$ de cálcio com os piores CMMS determinados quando se utilizou $0,28 \%$ de Pdisp.

De modo geral, verificou-se que o desempenho das aves (36 a 42 dias) que receberam dieta com $500 \mathrm{ftu} / \mathrm{kg}$ e os menores níveis de cálcio e Pdisp avaliados (0,46 e 0,23\%, respectivamente) foi semelhante ao desempenho das aves alimentadas com dietas sem fitase e níveis nutricionais recomendados por Rostagno et al. (2005). Entretanto, a redução do cálcio e Pdisp para 0,56 e 0,28\%, respectivamente, não prejudicou a EMAn e o CMMS e ainda melhorou a mineralização óssea, portanto, são os níveis mais adequados para as aves em fase final.

\section{Conclusões}

Os níveis nutricionais de cálcio e fósforo disponível da ração podem ser reduzidos com a suplementação com fitase ( $500 \mathrm{ftu} / \mathrm{kg}$ ). Na fase de crescimento (22 a 35 dias) a redução do cálcio e fósforo disponível para 0,52 e 0,26\%, respectivamente, não comprometeu o desempenho, a mineralização óssea, a energia metabolizável aparente corrigida pelo balanço de nitrogênio e o coeficiente de metabolizabilidade da matéria seca. Na fase final (36 a 42 dias), a redução do cálcio e fósforo disponível para 0,56 e $0,28 \%$, respectivamente, não compromete o desempenho, a energia metabolizável aparente corrigida pelo balanço de nitrogênio e o coeficiente de metabolizabilidade da matéria seca e melhora a mineralização óssea.

\section{Agradecimentos}

Ao Conselho Nacional de Desenvolvimento Científico e Tecnológico $(\mathrm{CNPq})$ pelo financiamento do projeto e à Fundação de Amparo à Pesquisa do Estado de Minas Gerais (FAPEMIG) pelo apoio financeiro por meio do Programa Pesquisador Mineiro (PPM).

\section{Referências}

ASSOCIATION OF OFFICIAL ANALYTICAL CHEMIST - AOAC. Official methods of analysis. 18.ed. Maryland, 2005. 1094p. BALLAM, G.C.; NELSON, T.S.; KIRBY, L.K. Effect of fiber and phytate source and of calcium and phosphorus level on phytate hydrolysis in the chick. Poultry Science, v.63, n.2, p.333-338, 1984.

CARDOSO JUNIOR, A.; RODRIGUES, P.B.; BERTECHINI, A.G. et al. Levels of available phosphorus and calcium for broilers from 8 to 35 days of age fed rations containing phytase. Revista Brasileira de Zootecnia, v.39, n.6, p.1237-1245, 2010.

CHOCT, M. Enzymes for the feed industry: past, present and future. World's Poultry Science Journal, v.62, n.1, p.5-15, 2006. EDWARDS JUNIOR, H.M. Dietary 1,25-dihydroxycholecalciferol supplementation increases natural phytate phosphorus utilization in chickens. Journal of Nutrition, v.123, n.3, p.567-577, 1993 .

GOMIDE, E.M.; RODRIGUES, P.B.; FREITAS, R.T.F. et al. Planos nutricionais com a Utilização de aminoácidos e fitase para frangos de corte mantendo o conceito de proteína ideal nas dietas. Revista Brasileira de Zootecnia, v.36, n.6, p.1769-1774, 2007. 
JORDÃO FILHO, J.; SILVA, J.H.V.; FERNANDES, A.C. et al. Níveis de fósforo disponível e de fitase na ração de frangos de 22 a 42 dias. In: CONFERÊNCIA APINCO DE CIÊNCIA E TECNOLOGIA AVÍCOLAS, 2006, Santos. Anais... Santos: FACTA, 2006. p.107.

LAN, G.Q.; ABDULLAH, N.; JALALUDIN, S. et al. Efficacy of supplementation of a phytase-producing bacterial culture on the performance and nutrient use of broiler chickens fed corn-soybean meal diets. Poultry Science, v.81, n.10, p.1522-1532, 2002.

LAURENTIZ, A.C.; JUNQUEIRA, O.M.; FILARDI, R.S. et al. Efeito da adição da enzima fitase em rações para frangos de corte com redução dos níveis de fósforo nas diferentes fases de criação. Ciência Animal Brasileira, v.8, n.2, p.207-216, 2007.

MATTERSON, L.D.; POTTER, L.M.; STUTZ, N.W. et al. The metabolizable energy of feed ingredients for chickens. Storrs: University of Connecticut, 1965. v.11, p.3-11. (Agricultural Experiment Station Research Report).

MITCHELL, R.D.; EDWARDS JUNIOR, H.M. Effects of phytase and 1,25-Dihydroxycholecalciferol on phytate utilization and quantitative requirement for calcium and phosphorus in young broiler chickens. Poultry Science, v.75, n.1, p.95-110, 1996.

NAGATA, A.K.; RODRIGUES, P.B.; RODRIGUES, K.F. et al. Uso do conceito de proteína ideal em rações com diferentes níveis energéticos, suplementadas com fitase para frangos de corte de 1 a 21 dias de idade. Ciência e Agrotecnologia, v.33, n.2, p.599-605, 2009.

QIAN H.; KORNEGAY, E.T.; DENBOW, D.M. Utilization of phytate phosphorus and calcium as influenced by microbial phytase, cholecalciferol, and the calcium:total phosphorus ratio in broiler diets. Poultry Science, v.76, n.1, p.37-46, 1997.

ROCHA, C.; OPALINSKI, M.; CASTRO, O.S. et al. Impacto da adição de fitase sobre a digestibilidade de dietas pré-iniciais com diferentes DGMs. In: CONFERÊNCIA APINCO DE CIÊNCIA E TECNOLOGIA AVÍCOLAS, 2006, Santos. Anais... Santos: FACTA, 2006. p.105

RODRIGUES, P.B.; MARTINEZ, R.S.; FREITAS, R.T.F. et al. Influência do tempo de coleta e metodologias sobre a digestibilidade e o valor energético de rações para aves. Revista Brasileira de Zootecnia, v.34, n.3, p.882-889, 2005.

ROSTAGNO, H.S.; ALBINO, L.F.T.; DONZELE, J.L. et al. Tabelas brasileiras para aves e suínos: composição de alimentos e exigências nutricionais. 2.ed. Viçosa, MG: UFV, 2005. 186p.

SCHOULTEN, N.A.; TEIXEIRA, A.S.; FREITAS, R.T.F. et al. Níveis de cálcio em rações de frangos de corte na fase inicial suplementadas com fitase. Revista Brasileira de Zootecnia, v.32, n.5, p.1190-1197, 2003.

SEBASTIAN, S.; TOUCHBURN, S.P.; CHAVEZ, E.R. et al. The effects of supplemental microbial phytase on the performance and utilization of dietary calcium, phosphorus, copper, and zinc in broiler chickens fed corn-soybeans diets. Poultry Science, v.75, n.6, p.729-736, 1996.

SEBASTIAN, S.; TOUCHBURN, S.P.; CHAVEZ, E.R. et al. Apparent digestibility of protein and amino acids in broiler chickens fed a corn-soybean diet supplemented with microbial phytase. Poultry Science, v.76, n.12, p.1760-1769, 1997.

SHAFEY, T.M.; McDONALD, M.W.; DINGLE, J.G. Effects of dietary calcium and available phosphorus concentration on digesta $\mathrm{pH}$ and on the availability of calcium, iron, magnesium and zinc from the intestinal contents of meat chickens. British Poultry Science, v.32, n.1, p.185-194, 1991.

SILVA, Y.L.; RODRIGUES, P.B.; FREITAS, R.T.F. et al. Níveis de proteína e fósforo em rações com fitase para frangos de corte, na fase de 14 a 21 dias de idade. 2. Valores energéticos e digestibilidade de nutrientes. Revista Brasileira de Zootecnia, v.37, n.3, p.469-477, 2008.

SILVA, Y.L.; RODRIGUES, P.B.; FREITAS, R.T.F. et al. Redução de proteína e fósforo em rações com fitase para frangos de corte no período de 1 a 21 dias de idade. Desempenho e teores de minerais na cama. Revista Brasileira de Zootecnia, v.35, n.3, p.840-848, 2006.

UNIVERSIDADE FEDERAL DE VIÇOSA - UFV. Sistema de análises estatísticas e genéticas - SAEG. Versão 5.0. Viçosa, MG, 1993. 59p. 